\title{
Levantamento estratigráfico das Formações Superficiais Cenozóicas no Planalto de Palmas (PR) e Água Doce (SC): subsídio ao estudo da evolução da paisagem a partir do Estágio Isotópico Marinho 3
}

\author{
Statigraphic Research about the Cenozoic Superficial Formations at \\ Palmas (PR) and Agua Doce (SC) Plateau: subsidy to the study of the \\ evolution of landscape from the Marine Isotopic Stage 3
}

\author{
Simone Guerra $\left.{ }^{1 *}\right)$ \\ Julio Cesar Paisani ${ }^{2}$
}

\section{Resumo}

O artigo apresenta informações do levantamento estratigráfico das Formações Superficiais Cenozóicas no Planalto de Palmas (PR) e Água Doce (SC): subsídio ao estudo da evolução da paisagem a partir do Estágio Isotópico Marinho 3 (EIM3), através da descrição de duas seções estratigráficas, bem como a utilização de informações da seção guia estabelecida previamente. Nas seções foram levantados depósitos de colúvio, colúvio-aluviais, solos enterrados e paleocanais de $1^{\mathrm{a}} \mathrm{e} 2^{\mathrm{a}}$ ordem colmatados. Os resultados evidenciaram registros estratigráficos com idades do Pleistoceno Superior ao Holoceno, referentes aos EIM 3,2 e 1. No geral, a paisagem possui sua evolução relacionada a fases alternadas de estabilidade/instabilidade, com processo de degradação/agradação e pedogênese com formação de Neossolos.

Palavras-chave: quaternário continental; estratigrafia; colúvio; paleossolo.

\section{Abstract}

The article presents information about the stratigraphic research of the Cenozoic Superficial Formations at Palmas (PR) and Água Doce (SC) Plateau: subsidy to the study of the landscape evolution from Marine Isotopic Stages (MIS3), through the description of four stratigraphic sections, and the use of guide section information

I MSc.; Geografia; Membro do Grupo de Pesquisa Gênese e Evolução de Superfícies Geomórficas e Formações Superficiais da Universidade Estadual do Oeste do Paraná, UNIOESTE, do campus de Francisco Beltrão; Endereço: Rua Maringá, I200, Bairro Vila Nova, CEP: 85605-010, Francisco Beltrão, Paraná, Brasil; E-mail: guerrasim@hotmail.com (*) Autor para correspondência.

2 Dr.; Geografia; Professor do Centro de Ciência Humanas da Universidade Estadual do Oeste do Paraná,, UNIOESTE, do campus de Francisco Beltrão; Endereço: Rua Maringá, 1200, Bairro Vila Nova, CEP: 85605010, Francisco Beltrão, Paraná, Brasil; E-mail: juliopaisani@hotmail.com 
previously established. The research pointed that, through local/regional organizing, the involved actors impregnated new uses of the territory, reinforcing power relations, increasing their ability to realize actions to meet their demands and interests. The results evidenced stratigraphic registrations from the Pleistocene Superior to Holoceno, referring to the MIS 3, 2 and 1. In general terms, the evolution of the landscape is related to alternate phases of stability / instability, with degradation / aggradation and pedogenesis with formation of Neosoils.

Key words: continental quaternary; stratigraphy; colluvium; paleosoils.

\section{Introdução}

As paisagens geomorfológicas são constituídas por formas de relevo geradas por diferentes processos ao longo do tempo. Esses processos são absorvidos pelas paisagens, gerando formas de relevos diferenciadas, como as encontradas na porção Sudoeste do Paraná e Noroeste de Santa Catarina. Tais paisagens vêm despertando interesse do Grupo de Pesquisa Gênese e Evolução de Superfícies Geomórficas e Formações Superficiais, cadastrado no CNPQ, o qual busca compreender a evolução do relevo da região (PAISANI et al., 2008; PAISANI et al., 2009; PAISANI et al., (submetido)).

A área pesquisada apresenta formações superficiais geradas tanto pelo intemperismo (autóctones) quanto pela erosão mecânica (alóctones). Nessa superfície, as formações superficiais apresentam depósitos de colúvio, colúvio-alúvios e paleossolos, que leva a pensar que a paisagem passou por eventos de degradação e agradação, intercalada por eventos de estabilidade ambiental (BIGARELLA et al., 1994).

A compreensão de períodos de estabilidade contínua ou de intercalação entre períodos de estabilidade e instabilidade, de ordem paleoclimática ou neotectônica (BIGARELLA; ANDRADE, 1965; MAGALHÃES; MOREIRA, s/d), são fundamentais para avaliar a sequência evolutiva das paisagens, as quais ainda são pouco compreendidas, sobretudo nas zonas tropicais e subtropicais, onde mudanças climáticas alteraram as taxas de equilíbrio (pedogênese) e desequilíbrio (morfogênese) (BIGARELLA; ANDRADE, 1965).

O levantamento e caracterização de seções estratigráficas no Planalto de Palmas (PR) e Água Doce (SC) revelaram depósitos de colúvio, colúvio - alúvios e paleossolos enterrados (PAISANI et al., 2008). Tais registros indicam que a evolução da paisagem da área se deu por meio de fases de estabilidade (pedogênese) intercaladas por fases de instabilidade (morfogênese).

Nesse contexto, o presente artigo, tem por objetivo apresentar o levantamento do registro estratigráfico das formações superficiais cenozóicas no Planalto de Palmas (PR) e Água Doce (SC).

\section{Área de Estudo}

A área de estudo localiza-se entre o Sudoeste do Paraná e Noroeste de Santa Catarina, mais especificamente na localidade de Horizonte, no limite entre os municípios de Palmas (PR) e Água Doce (SC) (Figura 1). Corresponde à Superfície Incompletamente Aplainada II (PAISANI et al., 2008), com altitudes que variam de 1.201 a 1.300 metros, inserida nos sistemas hidrográficos do rio Chopinzinho (PR) e Chapecozinho (SC). Insere-se na unidade fisiográfica designada de Terceiro Planalto 


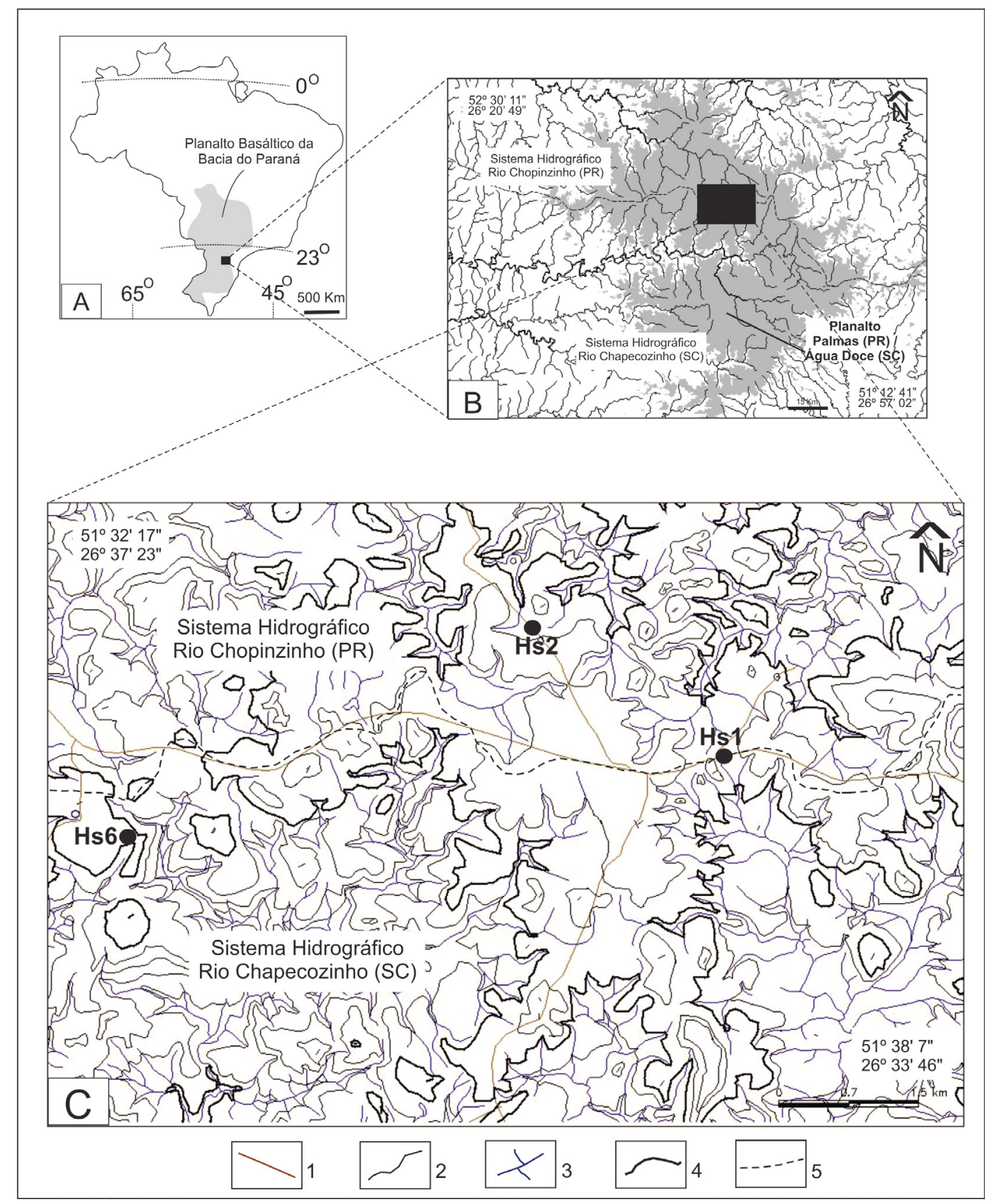

Figura I. Localização da área de estudo, no Planalto de Palmas (PR) / Água Doce (SC). A: Distribuição espacial da Formação Serra Geral. B: Planalto de Palmas (PR)/Água Doce (SC). C: Localização das seções estratigráficas descritas.

Fonte: Guerra, S. (20I2). 
Paranaense (MAACK, 1981), mantido principalmente por derrames da Formação Serra Geral da bacia do Paraná, de idade Cretácea (SCHNEIDER et al., 1974).

Inicialmente, nessa unidade fisiográfica, eram relacionados apenas derrames de natureza básica. Porém, Nardy et al. (2002), em estudos sobre rochas da bacia do Paraná, detectaram que a Formação Serra Geral é composta tanto por derrames básicos, quanto por derrames ácidos. Estes foram designados pelos autores de membros Palmas e Chapecó. Desse modo a área de estudo está inserida na zona de derrames de rochas ácidas do membro Palmas, constituída principalmente por riolito/riodacitos, que em alguns locais, chegam a aflorar na superficie (VOLKMER, 1999).

No local são encontrados solos rasos como Neossolos Litólicos e Neossolos Regolíticos com horizonte A húmico. São solos minerais pouco desenvolvidos, com profundidade variando entre 20 e 80 centímetros (Embrapa, 2006).

\section{Materiais e Métodos}

A metodologia baseou-se no levantar de duas seções estratigráficas, designadas de HS2 e HS6 (Figura 1), descritas em cortes de estradas, nos sistemas hidrográficos dos rios Chopinzinho (PR) e Chapecozinho (SC). Nestas seções, foram descritas unidades litológicas e unidades pedológicas, cujos critérios já foram utilizados por membros do grupo de pesquisa em outras seções estratigráficas, conforme Paisani et al., (2009), Paisani e Geremia (2010) e Paisani et al. (submetido a).

As unidades litológicas foram descritas com base nos seguintes procedimentos: a) nomenclatura das unidades por algarismos romanos da base para o topo; b) tipo de contato entre as camadas; c) tipo de estratificação; d) seleção;e) cor, utilizando-se a Carta de Munsell (2000); f) presença de raízes; g) bioturbação; h) presença de clastos e i) grau de preservação.

Já nas unidades pedológicas foram descritas as seguintes características: a) cor, utilizando-se Carta de Munsell (2000); b) consistência, sob três condições: material seco, úmido, e molhado; c) porosidade; d) transição inferior; e) presença de feições pedológicas; f) estrutura; g) resistência.

Nas seções estratigráficas descritas, foram coletadas amostras das unidades, para determinações laboratoriais como: a) granulometria,e b) datação pelo método do ${ }^{14} \mathrm{C}$. A granulometria, foi realizada no Laboratório de Análise de Formações Superficiais da UNIOESTE - Campus Francisco Beltrão, seguindo o método de peneiramento para fração grossa $(>0,062 \mathrm{~mm})$ e pipetagem para a fração fina $(<0,062 \mathrm{~mm})$, conforme rotina do laboratório baseada em Paisani (1998). Para esta análise, foram coletadas um total de 65 amostras nas unidades das seções descritas. Os resultados da granulometria foram plotados no diagrama triangular de Flemming (2000), para verificação da classificação textural das amostras (Figura 2, Quadro 1).

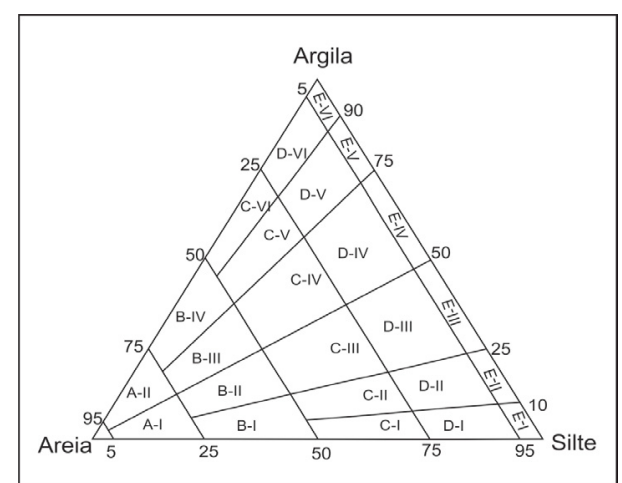

Figura 2. Diagrama triangular de Flemming (2000), para classificação textural das amostras 
Quadro I.Tipos de sedimentos e classes texturais contidas no diagrama triangular para a classificação textural proposta por Flemming (2000)

\begin{tabular}{|l|l|l|}
\hline Tipo de sedimento & Código & Classe textural \\
\hline Areia $(<5 \%$ lama $)$ & S & Areia \\
\hline $\begin{array}{l}\text { Areia levemente lamosa } \\
\text { (5-25\% lama) }\end{array}$ & A-I & Areia levemente siltosa \\
\hline & A-II & Areia levemente argilosa \\
\hline $\begin{array}{l}\text { Areia lamosa } \\
(25-50 \% \text { lama })\end{array}$ & B-I & Areia muito siltosa \\
& B-III & Areia siltosa \\
& B-IV & Areia argilosa \\
\hline Lama arenosa & C-I & Lama arenosa extremamente siltosa \\
$(50-75 \%$ lama $)$ & C-II & Lama arenosa muito siltosa \\
& C-III & Lama arenosa siltosa \\
& C-IV & Lama arenosa argilosa \\
& C-V & Lama arenosa muito argilosa \\
& C-VI & Lama arenosa extremamente argilosa \\
\hline & D-I & Lama levemente arenosa extremamente siltosa \\
& D-II & Lama levemente arenosa muito siltosa \\
& D-III & Lama levemente arenosa siltosa \\
& D-IV & Lama levemente arenosa argilosa \\
Lama levemente arenosa \\
$(75-95 \%$ lama)
\end{tabular}

Para datação do ${ }^{14} \mathrm{C}$, foram coletadas amostras na unidade pedogenizada da seção estratigráfica HS2, enquanto que para a HS6 a amostra foi coletada na unidade organo-mineral. Elas foram encaminhadas para datação pelo Laboratório de Carbono 14 do CENA/USP.

\section{Resultados e Discussão}

Os resultados se referem à descrição das seções estratigráficas HS2 e HS6, sendo apresentadas no item a seguir.

\section{Seção Estratigráfica HS2}

A seção HS2 se localiza no sistema hidrográfico do rio Chopinzinho (PR) (Figura 1), possui cerca de 1,60 $\mathrm{m}$ de espessura e aproximadamente $16 \mathrm{~m}$ de extensão. Os materiais encontrados apresentam contato abrupto com a isoalterita, rocha alterada com estrutura preservada (DELVIGNE, 1998), derivada de derrame vulcânico de natureza ácida, classificadas como riolito (PAISANI et al., submetido b). 
A seção apresenta três unidades caracterizadas por descontinuidades, designadas informalmente de sequências inferior, intermediária e superior. Essas sequências correspondem respectivamente a: colúvio pedogenizado (A), colúvio com quatro lentes subhorizontais (B) e interdigitação de colúvios (C) localmente com lentes, e pedorrelíquias de horizonte $A$, e pedogênese no topo da sequência. A seção registra, em sua porção central, duas gerações de paleocanal colmatados por colúvio - alúvio, uma em discordância com a isoalterita e outra em discordância com as sequências inferior e intermediaria (A e B) (Figura 3). alterado. Tal sequência corresponde à origem coluvial com fácies lama e silte (cód. MT), possivelmente devido a sua pedogênese. Nessa unidade, foram reconhecidos ainda três paleohorizontes enterrados desenvolvidos do topo para base: $\mathrm{Ab}, \mathrm{ACb}$ e $\mathrm{Cgb}$, com aproximadamente $70 \mathrm{~cm}$ de espessura, cores variando de bruno muito escuro (10 YR 2/ 2) a cinza escuro (7.5 YR 4/4).

A sequência intermediaria (B), corresponde a um depósito de colúvio com quatro lentes, cuja base está em contato abrupto com a sequência inferior. Tal sequência se encontra exposta na porção norte da seção, sobretudo entre as janelas 1 e 2, cuja matriz

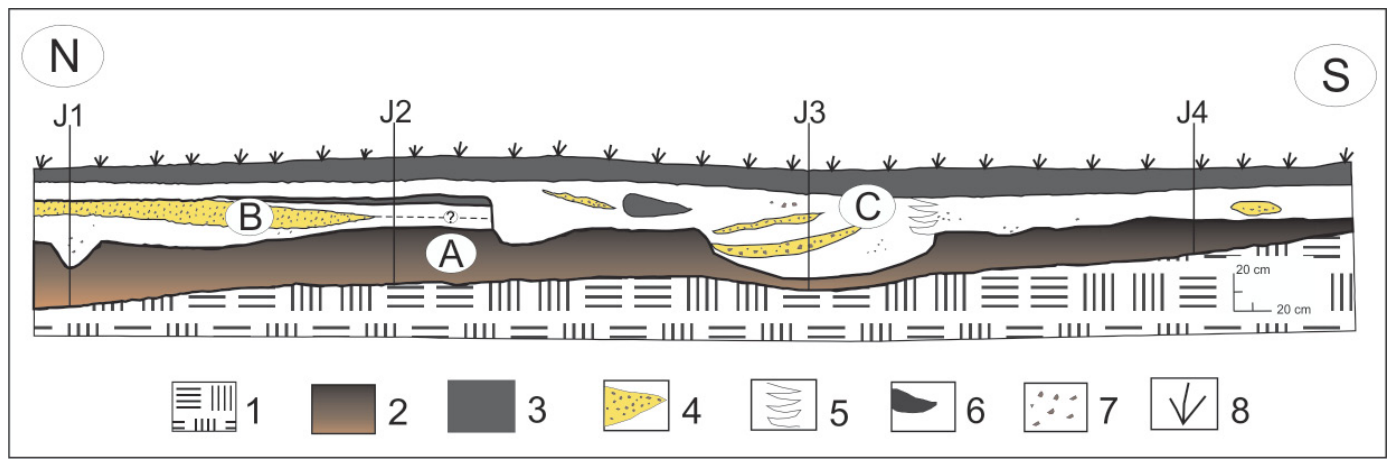

Figura 3. Representação esquemática da seção estratigráfica HS2, com 4 janelas onde foram coletadas amostras para análises de laboratório. I: riolito. 2: colúvio pedogenizado.3: horizonte A. 4: lente de cascalho. 5: interdigitação. 6: pedorrelíquia de horizonte $A$. 7:concentração de cascalho. 8: vegetação atual.A, B, C: sequências inferior, intermediária e superior. JI,...: Janela.

A sequência inferior (A) caracterizase como uma unidade litológica (camada I), pobremente selecionada de aproximadamente $70 \mathrm{~cm}$ de espessura, em contato abrupto (discordância erosiva) com a isoalterita do riolito. Apresenta textura de silte argiloso (classe E-III, código de Flemming, 2000) no topo, lama levemente arenosa siltosa (classe D-III) no centro e base, e exibe clastos esparsos de calcedônia e litorrelíquias com grau de alteração de moderada a completamente apresenta cor de bruno escuro (7.5 YR 3/3) a cinza muito escuro (7.5 YR 2.5/3) no topo. Essa é caracterizada por quatro lentes subhorizontais descontinuas lateralmente designadas de camadas II, III, IV, e V, todas de origem coluvial. A camada II corresponde a colúvio de textura lama levemente arenosa argilosa (classe D-IV) de cor bruno escuro (7.5 YR 3/3), caracterizada como fácies lama e areia (cód. SM). A camada III mostrase como lente de cascalho parcialmente 
alteradas, desaparecendo próximo a janela 2. Corresponde à fácies areia cascalhenta (cód. GyS), com matriz de textura de lama levemente arenosa siltosa (classe D-III) e cor bruno escuro (7.5 YR 3/4).

A camada IV faz contato com as camadas II e III. Apresenta textura de lama levemente arenosa argilosa (classe D-IV) e cor bruno escuro (7.5 YR 3/3) com clastos esparsos de calcedônia, fracamente alterada. Trata-se de fácies lama e areia (cód. SM), como a camada II, o que não permite precisar o limite entre as camadas IV e II.Já a camada $\mathrm{V}$ exibe geometria lenticular, desaparecendo próxima ao paleocanal. Esta possui textura de lama levemente arenosa argilosa (classe D-IV), de cor cinza escuro (7.5 YR 4/4), caracterizada por fácies lama e areia (cód.SM).

A sequência superior $(C)$ refere-se a uma interdigitação de colúvio - alúvios, transportados tanto de direção noroeste como de sudoeste, colmatando o paleocanal. Em seu interior, ocorrem quatro lentes descontinuas lateralmente, localizadas próximas ao paleocanal, algumas o preenchendo. As lentes são de cascalhos, similar a camada III, e uma delas similar a horizonte $\mathrm{A}$, levando a interpretá-la como pedorelíquia lenticular de horizonte A (Figura 3). No topo da sequência, desenvolveu-se um horizonte A, com $40 \mathrm{~cm}$ de espessura, cores de cinza muito escuro (7.5 YR 2.5/3) a bruno muito escuro (10 YR 2/2). A matriz da unidade, nas janelas 3 e 4, apresenta textura de silte argiloso (classe E-III) a argila siltosa (classe E-IV) no topo. Sobre o horizonte A, foi identificado, através da análise da quantidade de matéria orgânica (MO) e carbono, o desenvolvimento de uma unidade organomineral. No geral, a sequência superior (C) mostra-se com fácies lama e silte (cód. MT).

\section{Seção Estratigráfica HS6}

A seção HS6 se encontra a $\mathrm{SW}$ da seção HS5, apresenta $3,40 \mathrm{~m}$ de comprimento e 1,80 m de espessura (Figura 4), correspondendo à face transversal de jusante de paleocanal de $1^{\mathrm{a}}$ ordem colmatado. A seção chama à atenção por exibir no centro do canal estrutura de deformação complexa com uma zona de mistura de dois materiais distinguíveis primeiramente pela cor (unidades II e III).

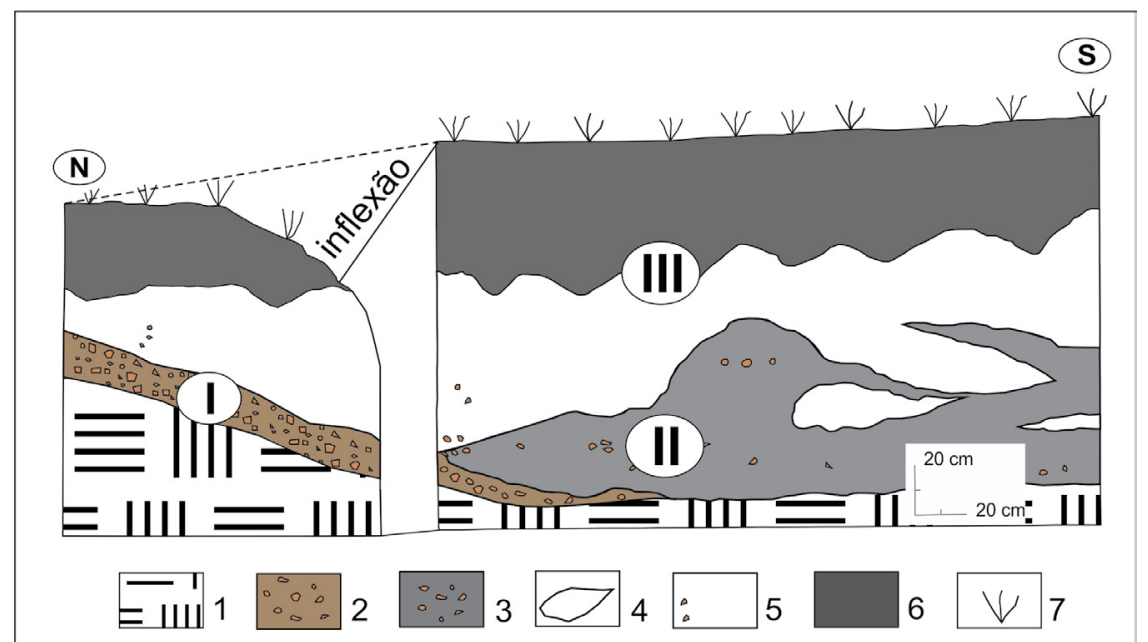

Figura 4. Representação esquemática da seção estratigráfica HS6 com individualização das camadas por algarismos romanos da base para o topo. I: riolito. 2: alúvio com cascalhos. 3: colúvio de paleohorizonte A. 4: lente coluvionar. 5: colúvio. 6: horizonte $\mathrm{A}$ húmico. 7: vegetação atual. 
A unidade I corresponde a material aluvial, sendo mais expressivo na base do canal a montante da seção, distribui-se de forma lenticular desaparecendo a SW. Apresenta $25 \mathrm{~cm}$ de espessura, contato abrupto de cor bruno amarelado (7.5 YR 5/4). A matriz da unidade apresenta textura de lama arenosa siltosa (classe C-III), com grande quantidade de cascalho, distribuído por toda a unidade, conferindo a esta, fácies lama cascalhenta com matriz suportada (cód. $m_{1}$ GyM).

A unidade II se distribui no centro do paleocanal (Figura 4), correspondendo a uma estrutura de deformação complexa. Contém lentes de material da unidade superior (unidade III), inserido a seu topo. Apresenta $40 \mathrm{~cm}$ de espessura, contato abrupto de cor castanho escuro amarelado (7.5 YR 3/3). Exibe variação textural na matriz de lama arenosa siltosa (classe C-III) a lama arenosa argilosa (classe C-IV), misturada com pequena quantidade de cascalho o que permite classificá-la como fácies lama cascalhenta com matriz suportada (cód. m1GyM). Esta unidade corresponde a colúvio de paleossolo com horizonte A húmico, o qual passou por movimento coletivo.

A unidade III corresponde a um colúvio espesso e pedogenizado em seu topo. Apresenta $1 \mathrm{~m}$ de espessura, contato abrupto de cor bruno escuro (7.5 YR 3/4) a preto (10YR 2/1) no topo. Possui textura variando de lama arenosa siltosa (classe C-III) na base e centro, à lama levemente arenosa argilosa (classe D-IV) no topo, caracterizando como fácies lama e areia (cód. MS).

No geral, a seção HS6 apresenta um canal de $1^{\text {a }}$ ordem que foi preenchido por sedimentos colúvio - aluvial com significativa quantidade de cascalhos, demonstrando grande energia no regime de fluxo. Esse preenchimento, ou colmatação do canal, foi gerado por movimentos de massa de elevada magnitude que rompeu de uma única vez a sequência de horizontes de solo (horizontes A e B), gerando sedimentação com inversão de horizontes. Primeiramente, depositou-se o horizonte $\mathrm{A}$ e na sequência o $\mathrm{B}$, ambos penecontemporâneos por permanecerem como evidência da estrutura complexa de deformação. Assim, a unidade apresenta dois materiais, na base uma estrutura de deformação e sobre esta, um colúvio cinza, reforçando a inversão de perfis de solo da encosta, com posterior movimentação coletiva deste para o canal. Após o período de colmatação do canal, e deposição inversa dos horizontes, inicia-se uma fase de estabilidade, com a instalação da pedogênese e seu desenvolvimento até a atualidade.

\section{Correlação Estratigráfica dos Registros Levantados nas Seções}

A correlação estratigráfica consiste na identificação da correspondência entre o registro estratigráfico das seções estudadas, objetivando a uma visão estratigráfica regional dos acontecimentos morfogenéticos e pedogenéticos verificados nas seções (MENDES, 1984).

Para realização da correlação informal entre as seções, buscou-se verificar se os registros estratigráficos das seções HS1, pesquisada por Paisani et al. (submetido) e aquelas da HS2, ambas situadas em fundos de paleovales de $2^{\text {a }}$ ordem. Também, buscou-se correlacionar os registros verificados nas seções HS1 e HS2 com os levantados na seção HS6, localizado em paleofundo de vale de $1^{\mathrm{a}}$ ordem.

Através dos dados cronológicos e baseados nas propriedades lito, pedo e aloestratigráfica (descontinuidades) das sequências, foi realizado correlações 
informais entre os registros identificados nas seções. Considerando que a HS1 exibe o maior número de datações do registro estratigráfico da localidade de Horizonte. Inicialmente buscou-se verificar correlação entre seu registro e o registro da HS2. As seções ocupam paleovales de $2^{\mathrm{a}}$ ordem, a HS1 em situação geomórfica próxima ao divisor de águas regional e a HS2 em interflúvio no alto vale do rio Chopinzinho.

Conforme Paisani et al. (submetido a) a HS1 exibe sete unidades litoestratigráficas, dividida em três sequências: inferior, composta pelas unidades I e II, intermediaria, com a unidade III e superior, formada pelas unidades IV a VII.

A seçãoHS2 como mencionada,também exibe três sequências: inferior, intermediaria e superior, baseados nas descontinuidades verificadas na seção. A sequência inferior é composta por uma unidade coluvial (unidade I), pedogenizada com desenvolvimento de neossolo flúvico com horizontes $\mathrm{Ab}, \mathrm{ACb}$ e $\mathrm{Cgb}$. Esse coluvionamento que gerou a unidade I entulhou o eixo de drenagem existente local, o qual ao passar do tempo foi se reinstalando novamente sobre a unidade I, removendo localmente os horizontes $\mathrm{Ab}$ e $\mathrm{ACb}$ de seu leito. Tal unidade foi datada em 30.600 anos AP (33.526 - 36.613 cal. AP) (Figura $5)$, revelando que anterior a esse período, houve fase de morfogênese com deposição de camadas de colúvio-alúvio, colmatando canais de drenagem de baixa ordem hierárquica, bem como camadas de coluvios, os quais, em um período mais estável foram sofrendo ações de processos pedogenéticos, formando paleohorizonte $\mathrm{A}$ ou neossolos flúvicos de idades compatíveis com o Pleistoceno Superior, tanto na HS2, quanto na HS1.

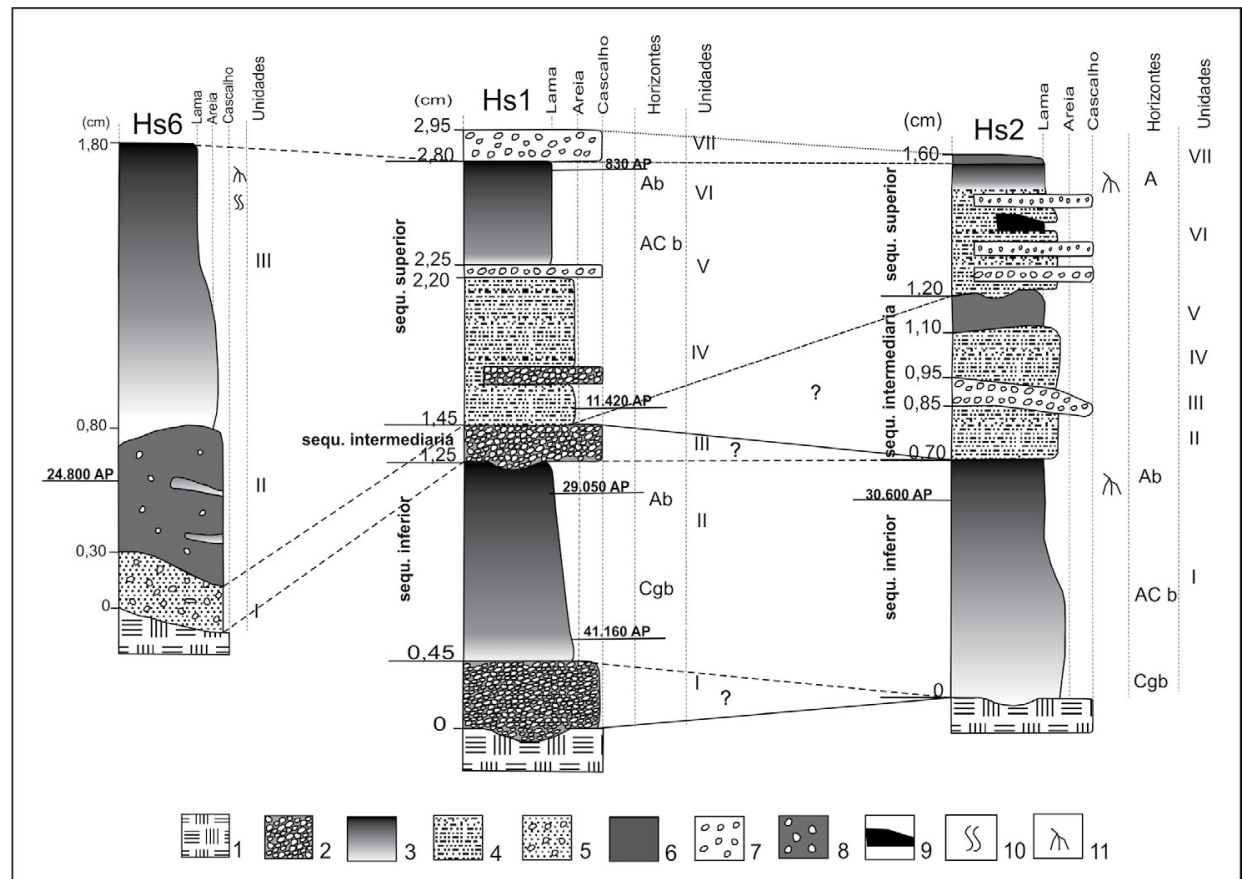

Figura 5. Correlação estratigráfica informal entre as seções HSI, HS2 e HS6. I: riolito. 2: cascalho lamoso. 3: neossolo regolítico e flúvico com horizonte $A$ húmico. 4: lama arenosa. 5: lama cascalhenta. 6: organo-mineral. 7: cascalho com matriz suportada. 8: organo mineral cascalhento. 9: pedorelíquia de horizonte A. 10: bioturbação. II: raízes. 
A sequência intermediária da HS2, revelou várias unidades coluviais (unidades II, III, IV e V) delgadas, em formato de lentes descontinuas lateralmente, originadas possivelmente em um período de chuvas concentradas gerando fluxos densos nas encostas, talvez corridas de terra. Essa sequência por vezes não chegou a entulhar o paleocanal, concentrando-se na porção noroeste da seção. Já na seção HS1 não se verifica tal registro, apenas um depósito aluvial, assentado sobre o talvegue de uma re-incisão do paleocanal (PAISANI et al., submetido a).

No geral, os registros verificados tanto na HS1, quanto na HS2, apresentam similaridades e diferenças. Desse modo, a HS1 apresenta um conglomerado aluvial (unidade I) mais antigo que 41.000 anos AP, não verificado na HS2, levando a considerar que o paleocanal da HS1 exercia mais energia, que o da HS2.

Já o período de pedogênese com desenvolvimento de neossolo flúvico foi registrado tanto na HS1, quanto na HS2, sugerindo mudança de regime hídrico dos paleofundos de vales, tendendo para colmatação no Estágio Isotópico Marinho 3 (EIM). A nova incisão do paleocanal na HS1, após o EIM 3 (< 25.000 anos AP), não foi registrada na HS2 após estabelecimento da sequência intermediária (camadas II a V). Enquanto que o canal da HS1 exibia conglomerado mostrando regime hídrico de alta energia o mesmo não se verifica na HS2. Assim a sequência intermediária de ambas as seções apresentam registros distintos, não passiveis de correlação (Figura 5).

$\mathrm{Na}$ sequência superior, verifica-se que a colmatação dos paleocanais estabelecida em ambas as seções durante o EIM 2 e 1, foi mais pronunciada na HS1, pois exibe cerca de $1,35 \mathrm{~m}$ de unidades coluviais, enquanto que a HS2 exibe em média $0,40 \mathrm{~cm}$ de espessura. Assim as propriedades da HS1 sugerem o estabelecimento de três unidades (IV, V e VI), e apenas uma unidade na HS2 (VI), porém correlatas entre si (Figura 5).

O último evento de pedogênese, datado de 830 AP (800 - 680 cal. AP) na HS1, também foi verificado na HS2. Sobre o produto da pedogênese, foi verificado em ambas as seções a ação antrópica, com o estabelecimento da unidade VII na HS1 e também VII na HS2 (Figura 5).

A seção HS6, por sua vez apresenta características passíveis de correlação com a sequência intermediária e superior da seção HS1. Datação do sedimento organomineral da unidade II da seção, revelou idade de 24.850 AP $(28.378$ - 30.938 cal. AP), indicando que nesse período, a unidade era um horizonte $A$ na encosta. Assim, a unidade I da seção seria mais jovem que a unidade II e estaria associada à colmatação da rede de drenagem que, pelos registros verificados nas seções HS1 e HS2, ocorreram nos EIM 2 e 1. Assim a unidade I da HS6, possivelmente fosse um canal de $1^{\text {a }}$ ordem funcional no EIM 2. Com a passagem do EIM 2 para o EIM 1, as intensas fases de morfogênese, atingiram as encostas do sistema hidrográfico do rio Chopinzinho tanto quanto do rio Chapecozinho, colmatando tanto canais de $2^{\mathrm{a}}$ como de $1^{\mathrm{a}}$ ordem de ambos os sistemas, apontando para um evento regional. Desse modo, a unidade I da HS6, por apresentar sedimentos aluviais de preenchimento de canal de $1^{\text {a }}$ ordem, seria correlata com a unidade III da HS1, na qual também foram verificados sedimentos aluviais de preenchimento de canal de $2^{\mathrm{a}}$ ordem. Porém, na HS1, verificou-se preenchimento por conglomerado, indicando um regime hídrico de alta energia, enquanto que a HS6 exibe 
um preenchimento menos denso, mais típico de paleocanal de $1^{\mathrm{a}}$ ordem de baixa energia (Figura 5).

No geral, a seção HS6 registra dois momentos importantes, primeiramente degradação nas encostas e agradação de canal de $1^{\mathrm{a}}$ ordem, formando a unidade I. Sobre essa a deposição de um colúvio de paleohorizonte A (unidade II), recoberto por um colúvio de horizonte B (unidade III), revelando na seção uma inversão de horizontes, fato não verificado na HS1. Porém, essa inversão de horizontes identificada na HS6 estaria associada às fases de morfogênese ocorrentes nos EIM 2 e 1, correlata com o espesso coluvionamento que gerou as unidades IV, V e VI na HS1 e ao último evento de pedogênese, datado de 830 AP (800 - 680 cal. AP) na HS1 (Figura 5).

Desse modo, os registros estratigráficos das sequências, intermediária e superior, identificados tanto na HS6, quanto na HS2 e HS1, indicam que nesse período a morfogênese foi mais intensa que a pedogênese, colmatando tanto canais de $2^{\mathrm{a}}$ como de $1^{\mathrm{a}}$ ordem, diferenciando-os apenas pela intensidade dos fluxos, mais intensos nos canais de $2^{\mathrm{a}} \mathrm{e}$ menos intensos nos de $1^{\text {a }}$ ordem.

\section{Evolução da Paisagem da Área de Estudo a partir de 41.000 anos AP}

Os registros estratigráficos verificados na área de estudo, revelam que de 41.000 anos AP há 25.000 anos AP, correspondente ao EIM 3 (Pleistoceno Superior) a atuação da pedogênese foi mais expressiva que a morfogênese, com períodos de estabilidade, formando neossolos flúvicos com horizonte $\mathrm{A}$ húmico tanto nas encostas, quanto nos fundos de vales de $2^{\mathrm{a}}$ ordem. Tal fato foi verificado nas seções estudadas, principalmente HS1 e HS2, as quais apresentavam nesse período canais de drenagem de $2^{\mathrm{a}}$ ordem, de fluxos perenes. Esses canais por vezes, foram colmatados entre 41.000 e 25.000 anos AP, provavelmente por mudanças nas condições ambientais. Após a colmatação dos canais, a paisagem segue um período de estabilidade ambiental, com desenvolvimento de neossolos com horizonte $\mathrm{A}$ húmico. Registros de mudanças climáticas globais e hemisféricas sugerem que nesse período a região sul do Brasil, apresentava temperaturas média inferiores que as atuais, onde as condições ambientais, possivelmente apresentasse clima mais quente e seco no início da deposição, mudando para mais frio e úmido no final, contribuindo para o desenvolvimento da pedogênese e formação de neossolos (OLIVEIRA et al., 2006). Fases de coluvionamento e pedogênese nesse período, também foram registradas no Segundo Planalto Paranaense (CAMARGO, 2005).

De 25.000 anos AP há 11.000 anos AP (EIM 2) são registradas tanto fases de morfogênese, quanto à manutenção da pedogênese do EIM 3. A manutenção da pedogênese foi verificada na seção HS1, talvez pelo fato de se encontrar no divisor regional, mantendo-se mais estável que os interflúvios (Figura 6). Já na seção HS2, a manutenção da pedogênese do EIM 3 não se manteve, possivelmente por estar inserida no interflúvio, onde a morfogênese foi mais significativa, formando unidades coluviais. No geral, as seções estudadas, apresentam nesse período, a formação de unidades coluviais e colúvio-aluviais, com colmatação de canais de $1^{\mathrm{a}}$ e $2^{\mathrm{a}}$ ordem, ocasionados principalmente por intensa degradação nas encostas, e posterior agradação dos fundos dos vales, interferindo tanto no sistema hidrográfico do rio Chopinzinho (PR), quanto do rio Chapecózinho (SC). 


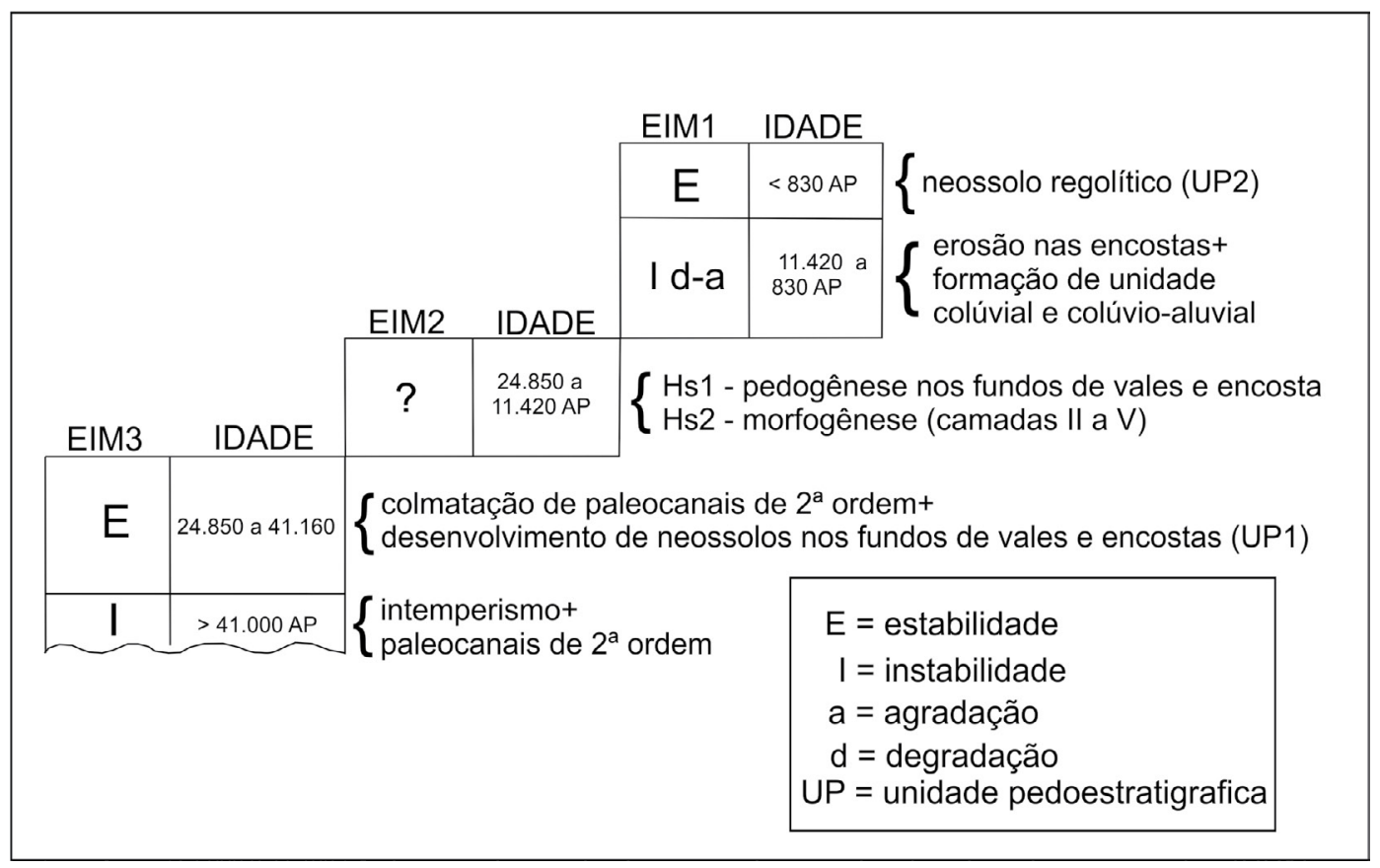

Figura 6. Fases de instabilidade/estabilidade e registros verificados na paisagem do Planalto de Palmas (PR) e Água Doce (SC), a partir do EIM 3

Após 11.000 anos AP, no EIM 1 (Holoceno), a paisagem da área de estudo continua sendo influenciada por processos morfogenéticos, principalmente movimentos de massa e escoamento superficial. O produto desses processos contribui para colmatação de paleofundo de vale e formação de unidades coluviais, mais ou menos espessas, dependendo de onde está inserida a seção. Posterior ao período de intensa morfogênese (instabilidade), possivelmente após 1.000 anos AP, correspondendo ao último milênio o ambiente local entra em equilíbrio (estabilidade) com atuação da pedogênese, formando Neossolos regolíticos com horizonte A húmico (PAISANI et al., submetido a).

De modo geral, a paisagem da área de estudo de 41.000 anos AP a atualidade, teria sua gênese e evolução ligada a fases alternadas de estabilidade/instabilidade, melhor exemplificado na figura 6. De fato, os registros estratigráficos evidenciados na área de estudo podem ser correlatos com registros estratigráficos identificados no Segundo Planalto Paranaense, na região de Santa Catarina e em setores da região sudeste do país, sugerindo que as fases de estabilidade/ instabilidade possuem um sinal regional, com pequenas variações, específico de cada local (OLIVEIRA et al., 2006; CAMARGO, 2005; LIMA, 2010; PAISANI et al., submetido a e b).

\section{Conclusão}

Nas seções estudadas foram identificados registros estratigráficos como paleossolos, depósitos coluviais e colúvio aluviais. Os paleossolos datados trazem idades do EIM 3 referentes ao Pleistoceno Superior, evidenciando um período de equilíbrio no ambiente (estabilidade) com instalação da 
pedogênese, formando NEOSSOLOS flúvicos nos fundos de vales de $2^{\mathrm{a}}$ ordem, e Neossolos regolíticos com horizonte A húmico nas encostas.

Entre o EIM 2 e 1, verificou-se a atuação de períodos de manutenção da pedogênese, com períodos de intensa morfogênese (instabilidade), ocasionando erosão (degradação) das encostas e colmatação (agradação) dos fundos de vale de baixa ordem hierárquica $1^{\mathrm{a}}$ e $2^{\mathrm{a}}$ ordem, formando depósitos colúvio - aluviais bem como coluviais, fato que perdurou até aproximadamente 1.000 anos AP. De fato, após 1.000 anos AP, correspondendo ao último milênio o ambiente local entra em equilíbrio (estabilidade) com atuação da pedogênese, formando Neossolos regolíticos com horizonte A húmico.

De maneira geral, o levantamento do registro estratigráfico na área de estudo, revelou informações importantes a cerca dos eventos responsáveis pela formação e remodelamento da paisagem da área. Tais eventos indicam que a paisagem possui sua evolução relacionada a fases alternadas de estabilidade/instabilidade, com processo de degradação/agradação e pedogenêse com formação de NEOSSOLOS. Porém, dúvidas restaram a respeito do EIM 2, principalmente sobre a fase em que teria sido predominante, a morfogênese ou a pedogênese, não claro nos registros estudados. Já no EIM 1, a dúvida fica em relação a morfogênese, até que ponto ela foi atuante na paisagem, e quando de fato inicia-se a pedogênese. No geral, verificou-se que a maioria dos registros identificados na área de estudo, possuem uma abrangência regional, como a maior influência da pedogênese no EIM 3, formando NEOSSOLOS com horizonte A húmico, e a maior atuação da morfogênese, registrando pulsos de pedogênese em alguns locais, nos EIM 2 e 1.

\section{Referências}

BIGARELLA,J.J.; BECKER R. D.; PASSOS E. Paisagem Cárstica.In: Estrutura e origem das paisagens tropicais e subtropicais. v.1. Florianópolis UFSC. 1994. p. 242-308.

BIGARELLA, J. J.; ANDRADE, G. O. Contribution th the study of the Brazilian Quaternary. In: The Geological Society of America, Special Paper, n.84, 1965. p. 433-451.

DELVIGNE, J. E. Atlas of micromorphology of mineral alteration and weathering. The Canadian Mineralogy. Special Publication 3 ORSTOM, 1998. 494p.

CAMARGO, F. M. O significado paleoambiental de sequência pedossedimentar em baixa encosta: o caso dos paleossolos Monjolo - Lapa - PR. 2005. 318 f. Tese (Doutorado em Geografia) - Universidade Federal de Santa Catarina, UFSC, Florianópolis, 2005.

EMBRAPA - Empresa Brasileira de Pesquisa Agropecuária. Centro Nacional de Pesquisa em Solos. Sistema Brasileiro de Classificação de Solos. 2. ed. Brasília: Embrapa Produção de Informação, Rio de Janeiro: Embrapa Solos, 2006.306p. 
FLEMMING, B. W. A revised textural classification of gravel-free muddy sediments on the basis ternary diagrams. Continental Shelf Research, n.20, p.1125-1137, 2000.

GUERRA, S. Abrangência espacial e temporal da morfogênese e pedogênese no Planalto de Palmas (PR) e Água Doce (SC): Subsídio ao estudo da Evolução da Paisagem Quaternária. 2012. [S.i.]. Dissertação (Mestrado em Geografia) - Universidade Estadual do Oeste do Paraná, UNIOESTE, Francisco Beltrão, 2012.

LIMA, G. L. Estratigrafia e Palinologia de depósitos turfosos e alúvio - coluviais Quaternários no Parque Estadual da Serra do Tabuleiro e Planalto de São Bento do Sul, Santa Catarina. 2010. [S.i.] Tese (Doutorado em Geografia) - Universidade Estadual de Santa Catarina, UFSC, Florianópolis, 2010.

MAACK, R. Geografia Física do Estado do Paraná. 2. ed. Rio de Janeiro: Jose Olympio, 1981. 450p.

MAGALHÃES, J. R.; MOREIRA, P. F. Eventos de "Desequilíbrio Morfodinâmico" na Evolução Geomorfológica de Minas Gerais - O caso de Teófilo Otoni/Caraí - Região Noroeste do Estado. Geonomos, v.6, p. 23-32, s/d.

MENDES, J. C. Elementos de Estratigrafia. São Paulo: EDUSP, 1984. 566p.

MUNSELL SOIL COLLOR CHART. Baltimore, Munsell Collor Company, Tab. 2000.

NARDY, A.J. R.; OLIVEIRA, M.A. F. Geologia e Estratigrafia da Formação Serra Geral. Revista Geociências, São Paulo, v.21, n.112, p. 15 - 32, 2002.

OLIVEIRA,M.A.T.; PESSENDA,L.C.A.R.;BEHLING,H.; LIMA, G.L.; FERREIRA, G. M.S.S. Registro de Mudanças Ambientais Pleistocênicas e Holocênicas em depósitos de Cabeceira de Vale: Campo Alegre, Planalto Norte Catarinense (SC). Revista Brasileira de Geociências, v.36, n.3, p.474-487, 2006.

PAISANI,J.C. Descontinuidades hidrológicas, escoamento superficial e desenvolvimento de incisões erosivas em áreas de cabeceira de drenagem: estudo de caso na Colônia QueroQuero, Palmeira, 1998. Dissertação (Mestrado em Geografia) - Universidade Federal de Santa Catarina, UFSC, Florianópolis, 1998.

PAISANI, J. C.; PONTELLI, M. E.; ANDRES, J. Superfícies Aplainadas em Zona Morfoclimática Subtropical úmida no Planalto Basáltico da Bacia do Paraná (SW Paraná/ NW Santa Catarina): Primeira Aproximação. Geociências, São Paulo, n.4, v.27, p.541-553, 2008.

PAISANI, J. C.; PONTELLI, M. E.; BERTOLDO, E.; BASSO, G. Resultados Preliminares da Caracterização de Seção Pedoestratigráfica em Palmas / PR. In: SIMPÓSIO PARANAENSE DE PÓS-GRADUAÇÃO EM GEOGRAFIA, 4., 2009, Marechal Cândido Rondon. 2009. Anais... Marechal Cândido Rondon, 2009. 10p. CD-ROM. 
PAISANI, J. C.; GEREMIA, F. Evolução de Encostas no Planalto Basáltico com base na Análise de Depósitos de Colúvio - Médio Vale do rio Marrecas, SW do Paraná. Geociências, São Paulo, v. 29, n. 3, p. 321-334, 2010.

PAISANI, J. C.; PONTELLI, M. E.; CALEGARI, M. R. Evolução de Bacias de baixa ordem Hierárquica no Planalto de Palmas/Água Doce (Sul do Brasil) nos 41.000 anos AP - O caso da seção HS1. Mercator, Ceará. (prelo a).

PAISANI,J. C.; PONTELLI, M. E.; CALEGARI, M. R. Contribuição para Reconstrução de Paleoperfis de Alteração no Planalto de Palmas/ Água Doce - Sul do Brasil. Mercator, Ceará. (prelo b).

SCHNEIDER, R. L. Revisão Estratigráfica da Bacia do Paraná. In CONGRESSO BRASILEIRO DE GEOLOGIA, 28., 1974, Anais... 1974. p.41-65.

VOLKMER, S. Mineralogia e morfologia de coberturas de alteração desenvolvidas em rochas vulcânicas ácidas: os exemplos de Palmas e Pinhão, PR. 1999.184 f.Tese (Doutorado em Geoquímica e Geotectônica) - Instituto de Geociências, Universidade de São Paulo, USP, São Paulo, 1999. 